\title{
Enhanced oxygen consumption in Herbaspirillum seropedicae fnr mutants leads to increased NifA mediated transcriptional activation
}

\author{
Marcelo Bueno Batista ${ }^{*}$, Roseli Wassem³ ${ }^{3}$ Fábio de Oliveira Pedrosa', Emanuel Maltempi de Souza',
}

Ray Dixon ${ }^{2}$ and Rose Adele Monteiro ${ }^{1}$

\begin{abstract}
Background: Orthologous proteins of the Crp/Fnr family have been previously implicated in controlling expression and/ or activity of the NifA transcriptional activator in some diazotrophs. This study aimed to address the role of three Fnr-like proteins from $\mathrm{H}$. seropedicae SmR1 in controlling NifA activity and consequent NifA-mediated transcription activation.

Results: The activity of NifA-dependent transcriptional fusions (nifA::lacZ and nifB::lacZ) was analysed in a series of $H$. seropedicae fnr deletion mutant backgrounds. We found that combined deletions in both the fnrl and fnr3 genes lead to higher expression of both the nifA and nifB genes and also an increased level of nifH transcripts. Expression profiles of nifB under different oxygen concentrations, together with oxygen consumption measurements suggest that the triple fnr mutant has higher respiratory activity when compared to the wild type, which we believe to be responsible for greater stability of the oxygen sensitive NifA protein. This conclusion was further substantiated by measuring the levels of NifA protein and its activity in fnr deletion strains in comparison with the wild-type.

Conclusions: Fnr proteins are indirectly involved in controlling the activity of NifA in $\mathrm{H}$. seropedicae, probably as a consequence of their influence on respiratory activity in relation to oxygen availability. Additionally we can suggest that there is some redundancy in the physiological function of the three Fnr paralogs in this organism, since altered respiration and effects on NifA activity are only observed in deletion strains lacking both fnr 1 and fnr3.
\end{abstract}

Keywords: Herbaspirilum seropedicae, NifA, Fnr

\section{Background}

The endophytic diazotroph Herbaspirillum seropedicae SmR1 is a Beta-proteobacterium found in association with economically important crops such as rice, maize, sugar cane and sorghum [1,2]. H. seropedicae can fix nitrogen under micro-oxic and nitrogen limiting conditions and expression of $H$. seropedicae nitrogen fixation (nif) genes inside plant tissues has been demonstrated [3]. In $H$. seropedicae the nif genes are clustered in a contiguous region of 46 genes [4], comprising at least seven operons [1], whose products are essential for biosynthesis, maturation and assembly of the nitrogenase complex. The nitrogenase structural genes (nifHDK) are

\footnotetext{
* Correspondence: marcelo.buenobatista@gmail.com

${ }^{1}$ Department of Biochemistry and Molecular Biology, Universidade Federal do Paraná, P.O. Box 19046, Curitiba, PR 81531-990, Brazil

Full list of author information is available at the end of the article
}

located in the nifHDKENXHsero2847Hsero_2846fdxA operon. nifH encodes the iron $(\mathrm{Fe})$ protein while nifDK encodes the molybenum-iron (MoFe) protein.The nifB gene, which encodes a protein involved in the synthesis of FeMoco, is located in an operon with other nif-related genes. The $\sigma^{54}$-dependent transcriptional activator, NifA, a member of the bacterial enhancer binding family [5] is a master regulator of nif gene expression in $H$. seropedicae SmR1 [1]. Two sites for NifA binding and a consensus binding site for the RNA polymerase $\sigma^{54}$ holoenzyme were found in the promoters upstream nifB and nifH [6,7]. NifA responds to both fixed nitrogen and oxygen levels, being activated in response to limitation of these resources [8]. Once active, NifA activates transcription from nif promoters [9] including nifB and nifH (reviewed in [1]).

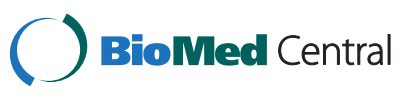

(c) 2015 Batista et al.; licensee BioMed Central. This is an Open Access article distributed under the terms of the Creative Commons Attribution License (http://creativecommons.org/licenses/by/4.0), which permits unrestricted use, distribution, and reproduction in any medium, provided the original work is properly credited. The Creative Commons Public Domain Dedication waiver (http://creativecommons.org/publicdomain/zero/1.0/) applies to the data made available in this article, unless otherwise stated. 
The Fnr protein, is a widespread transcriptional regulator that binds a $[4 \mathrm{Fe}-4 \mathrm{~S}]^{2+}$ cluster to monitor the oxygen status in the cell [10], and regulates the transcription of genes required for the metabolic switch in response to decreasing oxygen levels [11-13]. Orthologous proteins of the Crp/Fnr family $[11,14]$ have been previously implicated in controlling expression and/or activity of the NifA transcriptional activator in some diazotrophs [14-16]. In Klebsiella pneumoniae Fnr influences NifA activity through modulation of the mechanism by which the NifL repressor protein is sequestered to the membrane [15]. In Bradyrhizobium japonicum the Fnr-like protein, FixK ${ }_{1}$, negatively controls genes that are subject to NifA activation [16] suggesting that FixK $_{1}$, can repress transcription at NifA-dependent promoters. Another precedent for Fnr involvement in NifA activity was observed by Monteiro and co-workers [17], who showed that the activity of an amino-terminally truncated form of $H$. seropedicae NifA was influenced by Fnr when expressed in an Escherichia coli fnr-background.

The $H$. seropedicae genome [4] has three genes encoding for Fnr-like proteins [1] and a role for these Fnr orthologs in controlling the expression of the complete cytochrome $c$ branch of the electron transport chain has been demonstrated [18]. In this study we aimed to investigate the potential involvement of $H$. seropedicae Fnr proteins in the expression and activity of NifA and the consequences for transcriptional activation of other nif genes.

We found that combined deletions in both the $f n r 1$ and fur3 genes lead to higher expression of nifB::lac $Z$ and nifA::lac $Z$ transcriptional fusions and increased nifH transcription. We also show that the oxygen consumption rate in multiple fur deletion strains is higher than in the wildtype, which we believe to result in either higher stability or activity of the oxygen sensitive NifA protein and consequently increased transcriptional activation of nif genes.

\section{Results and discussion}

To analyze if the three fur genes in $H$. seropedicae influence either the expression level or the activity of NifA, we monitored expression of a nifB::lac $Z$ fusion, as a reporter of NifA activity. We compared nifB expression in the wild-type strain (SmR1) with a double deletion strain, which lacks both fnr1 and fnr3 (MB13) and a strain carrying deletions in all three $f n r$ genes (MB231). Multiple $f n r$ deletion strains were not analysed in these experiments since single gene deletions did not influence NifA activity. As nifB gene expression is tightly regulated by nitrogen and oxygen levels in the cell [6], the activity of the nifB::lac $Z$ reporter fusion is only observed when the cultures exhaust the supply of fixed nitrogen and oxygen becomes limited, as the culture reaches a high cell density. Although the fnr deletions impaired growth under these conditions as observed previously [18], the activity of the
nifB::lacZ fusion was significantly higher after 12-16 hours incubation in the strain lacking both $f n r 1$ and $f n r 3$ (MB13) and also in the triple fur deletion strain (MB231) when compared with the wild-type (Figure 1A). This suggests that either NifA expression or its activity is more highly induced in cultures of these multiple fur deletion strains.

We considered the possibility that the multiple fur deletion strains exhaust dissolved oxygen in the media faster than the wild type strain, thus leading to higher activity or stability of NifA in cultures of the fur deletion mutants. To examine this further, we assayed nifB::lac $Z$ activity in cultures grown in the absence of fixed nitrogen under defined initial oxygen concentrations of oxygen in the gas phase (Figure 1B). As anticipated, nifB expression was not detected under either $8 \%$ or $20.8 \%$ oxygen in both wild-type and the fnr triple deletion mutant, presumably because $H$. seropedicae NifA is inactivated at high oxygen
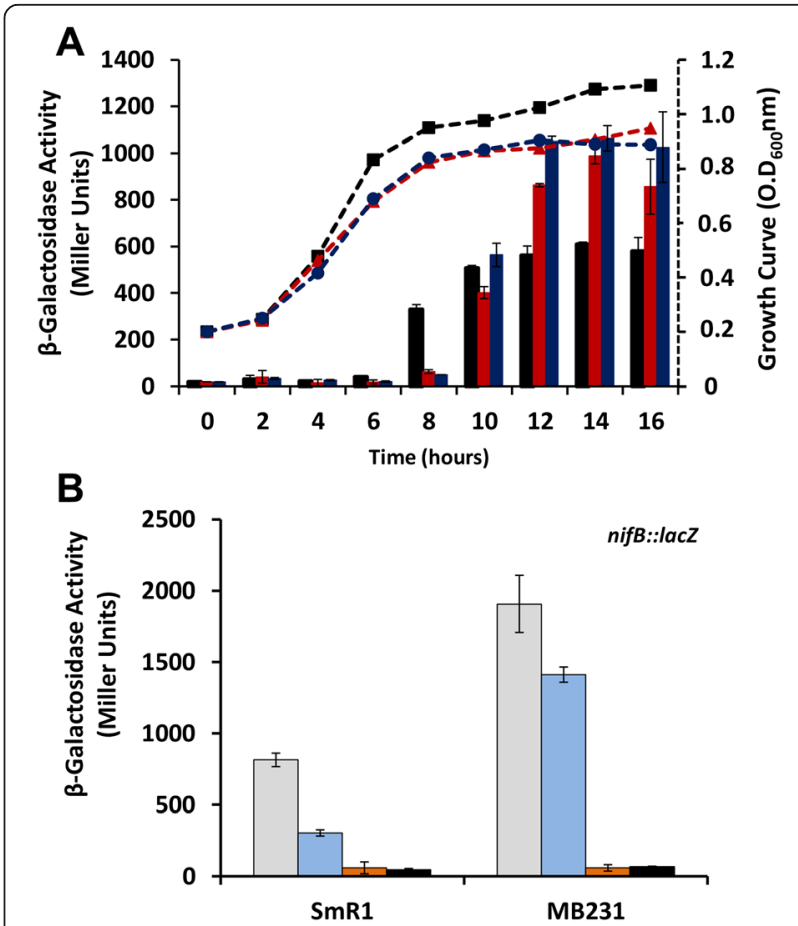

Figure 1 The nifB gene expression is enhanced in the fnr mutant strains from $H$. seropedicae. (A) The activity of the nifB:.lacZ fusion (primary y axis) was assayed using cells cultured in NFbHP-Malate liquid medium supplemented with $5 \mathrm{mM} \mathrm{NH}_{4} \mathrm{Cl}(6 \mathrm{ml}$ in $25 \mathrm{ml}$ bottles under air). Every two hours samples were taken for determination of $\beta$-galactosidase activity of the wild type strain (SmR1) (black bars), the double fnr 1 and fnr3 deletion strain (MB13) (red bars) and the triple fnr deletion strain (MB231) (blue bars). Samples were also taken for measuring the growth (O.D600-nm - secondary y axis) of the strains SmR1 (dotted black lines - squares), MB13 (dotted red lines - triangles) and MB231 (dotted blue lines - circles). (B) Activity of the nifB::/acZ fusion measured under the initial oxygen concentrations of $4.0 \%$ (light grey bars), 6.0\% (blue bars), $8.0 \%$ (orange bars) and 20.8\% (black bars) in liquid medium without addition of fixed nitrogen as describe in Methods. 
concentrations $[8,19]$. However, the activity of the nif$B:: l a c Z$ promoter fusion was markedly higher in the triple fnr deletion strain (MB231) compared with the parental strain, when cultures were incubated under an initial oxygen concentration of $4 \%$ or $6 \%$ in the gas phase (Figure 1B). To ensure that the increase of nifB expression observed in the mutant strains was NifA-dependent, we prepared single nif $A^{-}$and multiple deletion strains carrying a nifA deletion in addition to the fur mutations (Additional file 1) and confirmed that the influence of Fnr proteins on nifB promoter activation requires NifA protein (Additional file 2).

Since expression of the nifA gene itself is subject to autoactivation in $H$. seropedicae [20], we tested the influence of $f n r$ deletions on nifA expression using various nifA::lacZ promoter constructs (Figure 2). Transcriptional regulation of nifA is complex, since this $\sigma^{54}$ dependent promoter is subject to nitrogen regulation by the enhancer binding protein $\mathrm{NtrC}$ in addition to autogenous activation by NifA under oxygen-limiting conditions (see Figure 2A). Notably, single deletions in each of the three $f n r$ genes had no apparent influence on nifA expression. However, as in the case of nifB, an increase in promoter activation was apparent in the double furl, fnr3 deletion mutant (MB13) and the triple fur deletion strain (MB231) (Figure 2B). In all cases, promoter activation significantly decreased when cultures were grown in the presence of a high concentration of fixed nitrogen (Figure 2C), or when the -24 to -12 region of the promoter was disrupted (plasmid pRW22, Figure 2B), indicating that activation is rpoN-dependent and subject to nitrogen regulation by $\mathrm{NtrC}$ as expected [20]. In all cases, irrespective of the presence of $f n r$ mutations, nifA expression decreased when promoter constructs (plasmids pRWC and pRW3) carried mutations in the upstream activation sequence (UAS2) of the promoter (Figure 2B), presumably as a consequence of decreased autoactivation by NifA [20]. Overall, these results demonstrate that in the absence of both fnr1 and fnr3, activation of the nifA promoter is increased. Since higher expression of the nifA::lacZ fusion is not observed when the NifA binding site (UAS2) is deleted, it is likely that the increased expression results from autoactivation of the nifA promoter due to increased activity or stability of NifA protein.

Given that the nifA promoter is subjected to complex regulation, we designed experiments to confirm that NifA activity is enhanced in $f n r$ mutant strains. Firstly, using the combined $f n r^{-}$and nifA deletion strains described above (Additional files 1 and 2) we complemented the nifA mutation with nifA expressed ectopically from the lac promoter (plasmid pRAMM1), which is constitutive in H. seropedicae. In this complementation assay we observed that the levels of nifH mRNA were

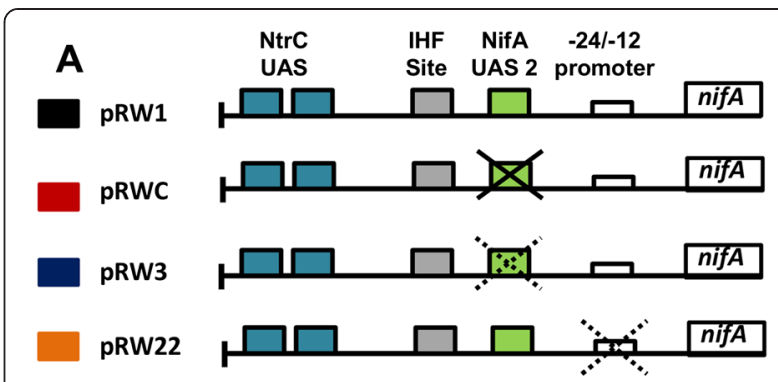

B
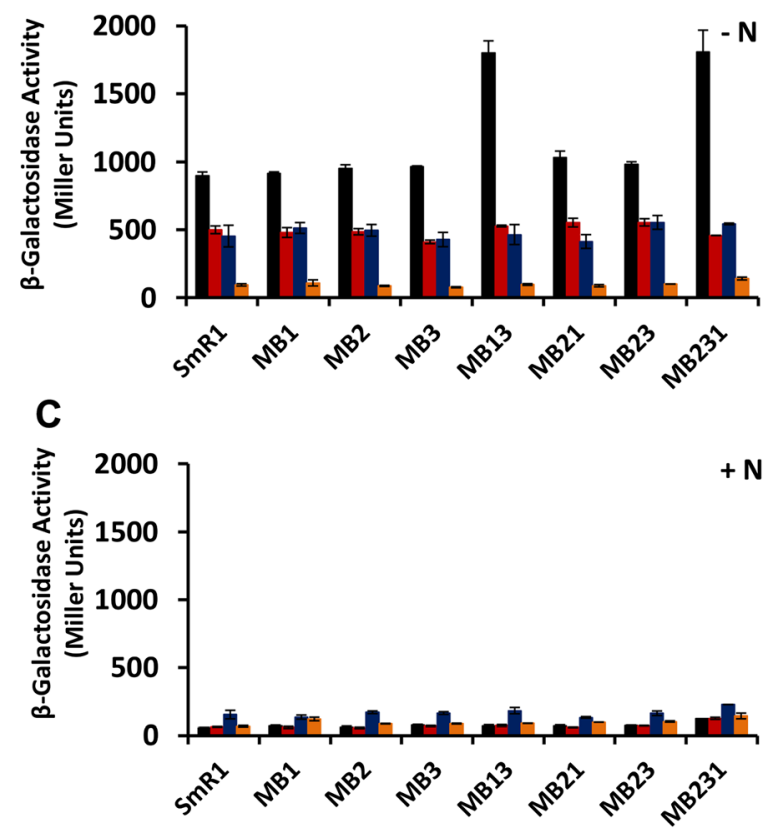

Figure 2 The nifA gene expression is enhanced in the fnr mutant strains from $H$. seropedicae. (A) Schematic representation of native and mutant nifA::lacZ fusions assayed for $\beta$-Galactosidase activity in fnr mutant strains is showed. Full crosses indicate deletions, while dotted crosses indicate point mutations. The $\beta$-Galactosidase activity of different nifA::lacZ transcriptional fusions in $\mathrm{H}$. seropedicae SmR1 and fnr

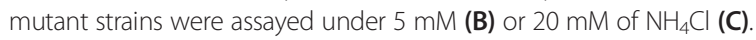
The colour code used for each transcriptional fusion in the bar graphs in $\mathbf{B}$ and $\mathbf{C}$ is represented in $\mathbf{A}$. Results showed are representative of two independent experiments.

higher in the fur deletion strains complemented with constitutively expressed NifA in comparison with the complemented strain containing wild-type $f u r$ alleles (Figure 3). This implies that an increase in NifA activity, rather than its expression, is responsible for increased activation of nif promoters in the fnr deletion mutants. Secondly, we constructed strains expressing NifA fused to a 3XFlag peptide to allow detection of the protein in both wild type and $f n r$ mutant backgrounds (Additional file 3). Western blots of strains carrying the nifA-3Xflag allele revealed higher levels of NifA expression in the double fnrl, fnr3 deletion (MBN5) and also in the triple fur deletion (MBN6) 


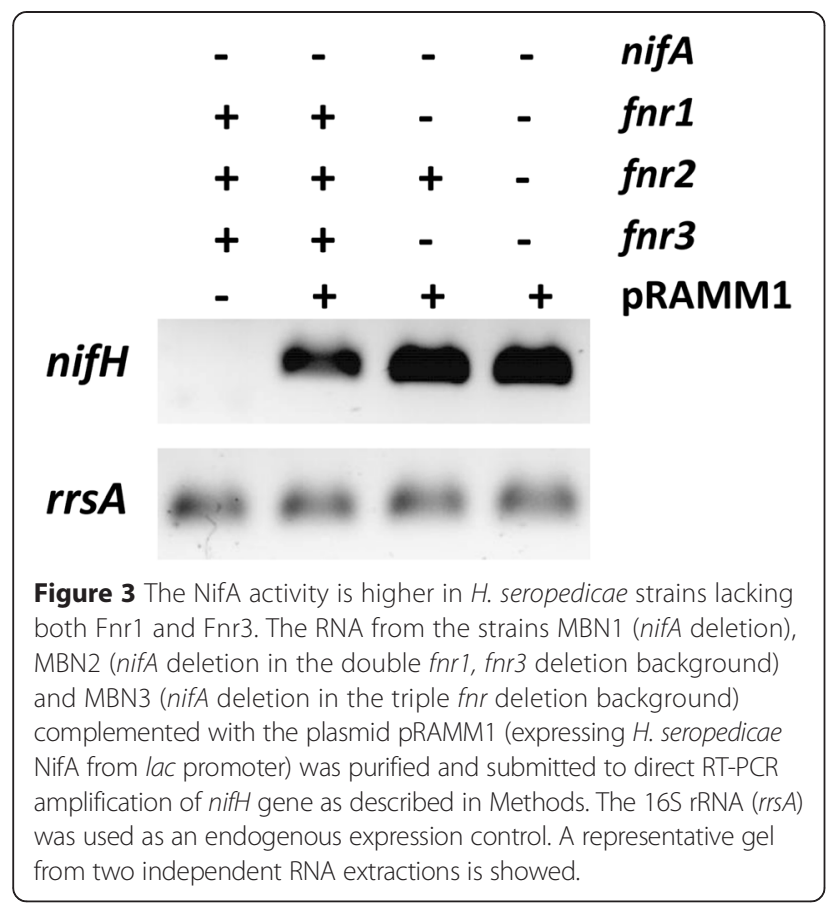

backgrounds compared with the strain carrying wildtype $f n r$ alleles (MBN4) (Figure 4). This confirms the additional level of autoactivation of the nifA promoter conferred by the multiple fur deletions (Figure 2B), again indicating that NifA activity is higher in the $f n r$ mutant strains.

As the H. seropedicae NifA protein is sensitive to oxygen, being inactivated and degraded upon exposure to $\mathrm{O}_{2}[8,19]$, we hypothesized that NifA might be protected in its active form in fur deletion strains if these strains exhibit a higher oxygen consumption rate. To further test this hypothesis we measured oxygen depletion during the growth of bacterial cultures in the same growth conditions as described for the assay of the nifA::lacZ fusions. We first analyzed the decrease in oxygen concentration in the gas phase of Suba-seal stoppered flasks (Figure 5A) and additionally compared the profiles of dissolved oxygen consumption using a Clark type electrode (Figure 5B). These assays revealed that the consumption of oxygen was higher in multiple fur deletion strains, implying that these strains have a higher respiratory rate when compared to the wild type (Figure 5). Notably, the oxygen consumption data in Figure 5A directly correlates with the increased activity of NifA observed in strains lacking both Fnr1 and Fnr3 (Figure 2B) implying that the absence of both these transcription factors results in higher respiration rates.

In a previous study, we showed that the triple fnr mutant is deficient in the expression of the cytochrome $c$-type branch of the electron transport chain [18]. An alternative route of electron transport from the quinol pool to oxygen

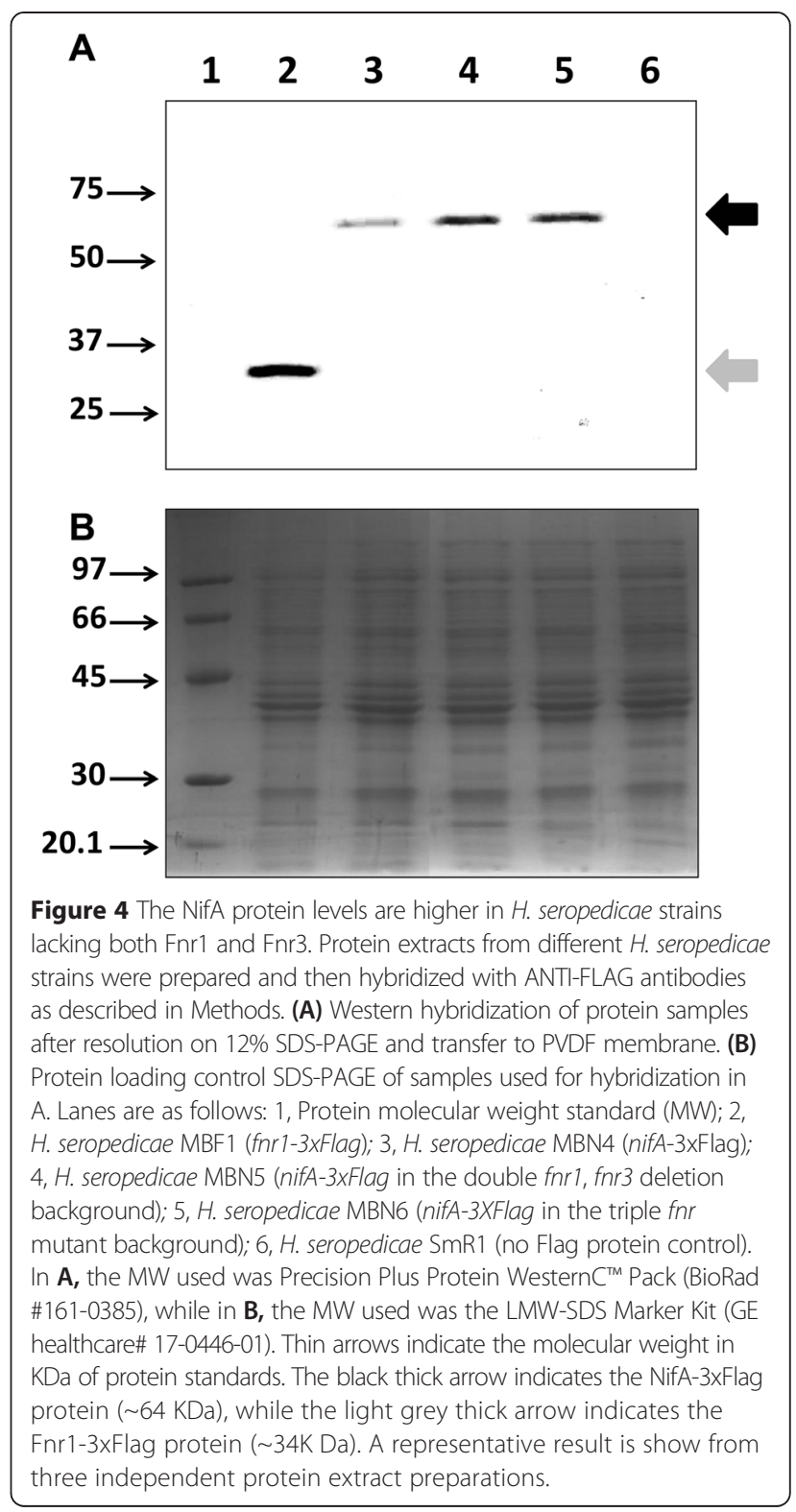

via the terminal quinol oxidases is likely to occur in the triple fur mutant. As the quinol branch of the respiratory chain results in a lower number of proton-translocation events it is conceivable that the activity of this branch, rather than the expression of the $b o_{3}$ and $b d$-type oxidases, is enhanced in the fur mutant strains to compensate for the lower level of energy production. This may result in increased electron flux through the respiratory chain and hence enhanced oxygen consumption as observed in our experiments.

We demonstrated previously that nitrogenase activity is severely impaired when the triple $f u r$ deletion strain is cultured in ammonium-limiting liquid medium, potentially as a consequence of energy depletion [18]. We also showed that diazotrophic growth is impaired in the fur 


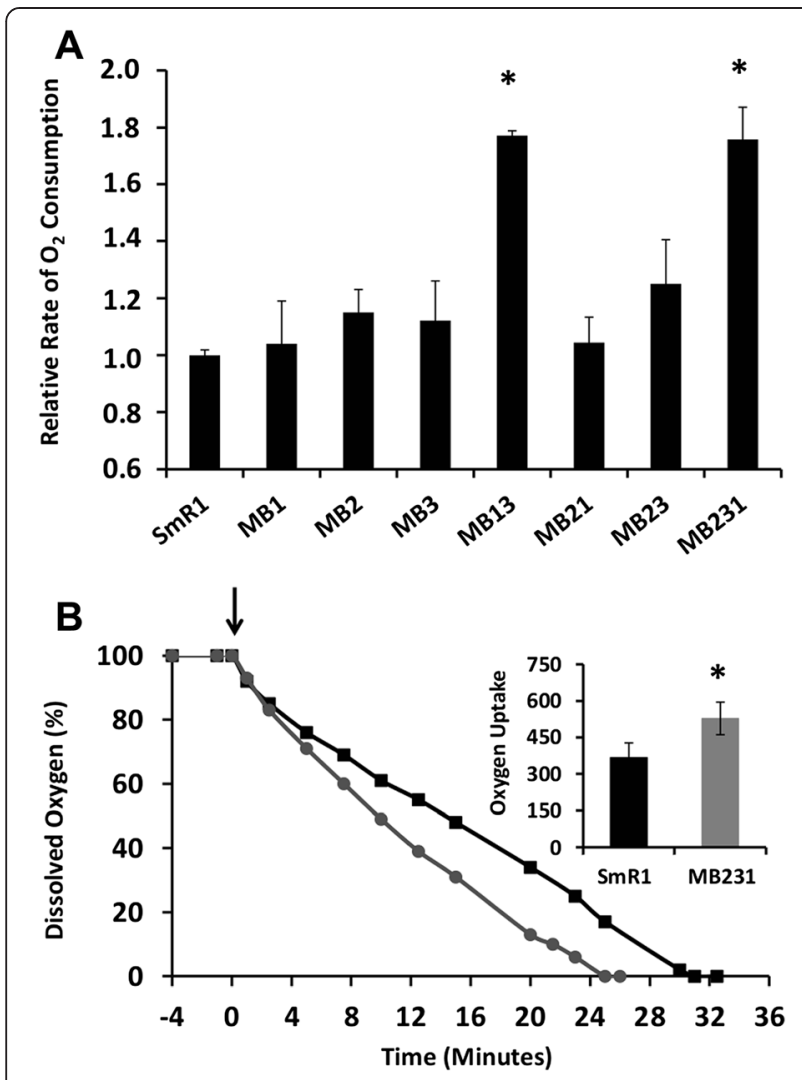

Figure $\mathbf{5}$ The oxygen consumption rate is higher in the $H$. seropedicae fnr mutant strains. (A) Gas phase oxygen consumption in $\mathrm{H}$. seropedicae SmR1 and fnr mutant strains. (B) Consumption of dissolved oxygen in liquid media of $H$. seropedicae strains SmR1 (black squares) and MB231 (grey circles) using a clark-type electrode. The arrow indicates addition of $100 \mu \mathrm{L}$ of cells into the electrode chamber containing $1.6 \mathrm{ml}$ of NfbHPMalate supplemented with $5.0 \mathrm{mM}$ of ammonium chloride. The inset shows the specific oxygen uptake rate (given as $\mu$ molar $\mathrm{O}_{2} \cdot \mathrm{mg}$ protein. $\mathrm{min}^{-1}$ ) in liquid cultures, which was calculated considering the oxygen solubility in water as $233 \mu \mathrm{M}$ [25]. The asterisks indicate statistical significance according to the Student's T-test $(P<0.05)$, derived from two independent experiments.

ablated strain, after subjecting cultures to severe nitrogen starvation [18]. Under these conditions, cultures divide at extremely low growth rates, requiring 24 days postinoculation to achieve an $\mathrm{OD}_{600}$ of $\sim 1.6$ (Additional file 4). However, it is notable that the triple fur mutant grew faster than the wild-type for the first 12 days of incubation under these conditions. Potentially, the enhanced rate of $\mathrm{O}_{2}$ consumption by the triple fur deletion allows higher levels of NifA activity and consequently higher nitrogenase activity during the 'early' stages of growth. However, it is possible that as the bacterial population increases and the oxygen levels in the culture drop further, the triple fur mutant strain can no longer maintain the necessary electron flux to support nitrogenase activity and as a consequence, diazotrophic growth is impaired.
In summary, these studies have not identified a direct role for the $H$. seropedicae Fnr proteins in regulating NifA activity and nitrogen fixation, but rather suggest that they may influence both, by means of altering the composition of the electron transport chain and the oxygen consumption rate. Since we only observe such effects in strains deleted for both fur 1 and fur3, there is apparently some redundancy in the physiological functions of the three fur paralogs in $H$. seropedicae. It is feasible that $H$. seropedicae can take advantage of the three fur genes to differentially modulate respiratory chain composition. This is likely to influence nitrogen fixation during different phases of growth and enable efficient adaptation during plant-bacterial colonization.

\section{Conclusions}

In this study we have used a combination of transcriptional and physiological approaches to address the role of the $H$. seropedicae Fnr proteins in influencing the expression and activity of NifA. In summary we found that Fnr1 and Fnr3 participate indirectly in modulating NifA stability as a consequence of alterations in the rate of $\mathrm{O}_{2}$ consumption. This mechanism can potentially allow the bacteria to fine tune nitrogen fixation in response to environmental cues.

\section{Methods}

Plasmids, bacterial strains and growth conditions

Plasmids and bacterial strains used are listed in Table $1 . H$. seropedicae strains were grown at $30^{\circ} \mathrm{C}$ in NFbHP-Malate medium [21] supplemented with $\mathrm{NH}_{4} \mathrm{Cl}$ as indicated. The antibiotics used were tetracycline $\left(10 \mu \mathrm{g} \mathrm{mL} \mathrm{m}^{-1}\right)$, streptomycin $\left(80 \mu \mathrm{g} \mathrm{mL}^{-1}\right)$, kanamycin $\left(500 \mu \mathrm{g} \mathrm{mL}^{-1}\right.$ for $H$. seropedicae and $50 \mu \mathrm{g} \mathrm{mL}^{-1}$ for E. coli), gentamicin $(500 \mu \mathrm{g} \mathrm{mL}$ for $H$. seropedicae) and nalidixic acid $\left(5 \mu \mathrm{g} \mathrm{mL}{ }^{-1}\right)$.

\section{Construction of nifA deletion and 3xFlag tagged strains}

To construct the C-terminal 3xFlag tagged NifA strains, we generated a nifA-3XFlag gene by cloning the complete nifA gene $(1629 \mathrm{bp})$ in frame with the 3xFlag sequence from a vector synthesized by the GenScript ${ }^{\bullet}$ Corporation (Table 1 ). To assist homologous recombination, a fragment of $647 \mathrm{bp}$ downstream of nifA was cloned adjacent to the 3xFlag tag sequence to generate an approximately $2.4 \mathrm{~Kb}$ fragment containing the nifA-3xFlag allele plus the downstream region. This fragment was then digested with BamHI, and subcloned into pK18mobsacBKm vector [22] to generate the suicide vector pK18nifAflag. A similar approach was used to generate a vector for C-terminal 3xFlag tagging of the furl gene, but a fragment of 1002 bp downstream of fur 1 gene was cloned adjacent to the 3xFlag tag sequence to generate a fragment of approximately $1.95 \mathrm{~kb}$ containing the fnr1-3xFlag allele plus the downstream region. This fragment was then subcloned into PJQ200SK suicide vector [23] to generate pJQfnr1Flag. To generate the nifA deletion vector, plasmid pRAM1T7 was digested with EcoRI and 
Table 1 Plasmids and strains used in this study

\begin{tabular}{|c|c|c|}
\hline Plasmids & Relevant characteristic & Source \\
\hline pLAFR3.18 & pLAFR vector containing the polycloning site of $p T Z 18 R, T c^{R}$ & [8] \\
\hline PRAMM1 & H.seropedicae NifA expressed from lac promoter & {$[26]$} \\
\hline pK18mobsacBKm & Allelic exchange suicide vector; mobilized by E. coli $\$ 17-1 \lambda$ pir, sacB, Km ${ }^{R}$ & {$[22]$} \\
\hline pJQ200SK & Allelic exchange suicide vector; mobilized by E. coli S17-1, sacB,Gm & [23] \\
\hline PRAM1T7 & H.seropedicae NifA in pT7-7 vector & This study \\
\hline pRAM1T7del & H.seropedicae NifA with a deletion of $576 \mathrm{bp}$ & This study \\
\hline pK18nifAdel & Xbal/BamHI fragment from pRAM1T7del & This study \\
\hline pUC57Simple-3xFlag & 5'-BamHI, Kpnl, Xhol - 3xFlag-Stop - HindIII, Sall, Xmal-3', Amp ${ }^{R}$ & Genscript $^{\oplus}$ Corporation \\
\hline pUC57nifAFlag & H. seropedicae nifA-3xFlag gene plus $647 \mathrm{bp}$ of the downstream region, $\mathrm{Amp}^{\mathrm{R}}$ & This study \\
\hline pK18nifAFlag & H. seropedicae nifA-3xFlag gene plus $647 \mathrm{bp}$ of the downstream region, Mob, SacB, $\mathrm{Km}^{\mathrm{R}}$ & This study \\
\hline pUC57fnr1Flag & H. seropedicae fnr1-3xFlag gene plus $1000 \mathrm{bp}$ of the downstream region, $\mathrm{Amp}^{\mathrm{R}}$ & This study \\
\hline pJQfnriFlag & H. seropedicae fnr1-3xFlag gene plus 1000 bp of the downstream region, Mob, SacB, Gm ${ }^{R}$ & This study \\
\hline pPW452 & lacZ fusion vector, $T c^{R}$, Mob & [27] \\
\hline pEMS140 & $T c^{R}$, Mob, nifB:.:lacZ fusion, nifB promoter cloned in pPW452 & [6] \\
\hline pRW1 & $T c^{R}$, Mob, nifA::lacZ fusion, nifA promoter cloned in pMP220 & {$[20]$} \\
\hline pRWC & pRW1, but with a 49 bp deletion including the UAS 2 site for NifA & {$[20]$} \\
\hline pRW3 & pRW1, but with a double mutation at the UAS 2 site for NifA (TGT $\rightarrow$ TCT and ACA $\rightarrow$ AGA) & {$[20]$} \\
\hline pRW22A & pRW1, but with a single mutation at the $-24 /-12$ promoter ( $G>T$ at -25 residues) & [20] \\
\hline Strains & Relevant characteristic & Source \\
\hline SmR1 & 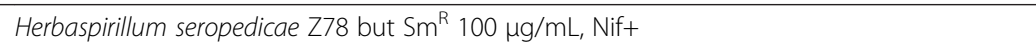 & [24] \\
\hline MB1 & Derived from SmR1 fnr 1 deletion & [18] \\
\hline MB2 & Derived from SmR1, fnr2 deletion & [18] \\
\hline MB3 & Derived from SmR1, fnr3 deletion & [18] \\
\hline MB13 & Derived from MB1, fnr1 and fnr3 double deletion & [18] \\
\hline MB21 & Derived from MB2, fnr1 and fnr1 double deletion & [18] \\
\hline MB23 & Derived from MB2, fnr2 and fnr3 double deletion & [18] \\
\hline MB231 & Derived from MB23, fnr1, fnr2 and fnr3 triple deletion & [18] \\
\hline MBN1 & Derived from SmR1, but with 576 bp deletion in the nifA gene & This study \\
\hline MBN2 & Double fnr1, fnr3 deletion, plus a 576 bp deletion in the nifA gene & This study \\
\hline MBN3 & Triple fnr deletion, plus a 576 bp deletion in the nifA gene & This study \\
\hline MBN4 & Derived from SmR1, but with a C-terminal 3xFlag nifA gene & This study \\
\hline MBN5 & Double fnr1, fnr3 deletion, plus a C-terminal 3xFlag nifA gene & This study \\
\hline MBN6 & Triple fnr deletion, plus a C-terminal 3xFlag nifA gene & This study \\
\hline MBF1 & Derived from SmR1, but with a C-terminal 3xFlag fnr1 gene & This study \\
\hline
\end{tabular}

re-ligated to yield the vector pRAM1T7del containing a deleted copy of nifA lacking $576 \mathrm{bp}$. Then an XbaI/BamHI fragment from pRAM1T7del was cloned into pK18mobsacB vector to generate the pK18nifAdel suicide vector.

The suicide plasmids generated for both tagging of nifA and fnr 1 and also for deletion of nifA gene were transferred to wild type $H$. seropedicae SmR1, and the fur deletion strains MB13 and MB231 strains by conjugation as described $[18,24]$. Single crossover strains were selected by antibiotic resistance. Double crossover strains were selected on plates containing 5\% sucrose and then tested for antibiotic marker sensitivity. The mutant strains sensitive to kanamycin or gentamicin and resistant to sucrose were analysed by PCR using specific primers as described (Additional files 1, 3 and 5). All primers used are listed in the Additional file 6.

\section{$\beta$-Galactosidase activity and transcriptional fusions}

$\beta$-Galactosidase activities of various nif promoter:lac $Z$ transcriptional fusions were assayed in $H$. seropedicae strains as previously described [6,20], except that the strains were grown in NFbHP-Malate liquid medium supplemented 
with $5 \mathrm{mM} \mathrm{NH}_{4} \mathrm{Cl}(6 \mathrm{ml}$ in $25 \mathrm{ml}$ cylindrical bottles under air). Under these conditions, the cultures exhaust the supply of fixed nitrogen and become oxygen limited resulting in formation of active NifA and nif gene expression.

Alternatively, $H$. seropedicae strains carrying the nif$B:: l a c Z$ fusion were assayed for $\beta$-galactosidase activity after incubation under defined initial oxygen concentrations. In summary, cultures with an $\mathrm{O} \mathrm{D}_{600}$ adjusted to 0.2 , were incubated for six hours in NFbHP-Malate without addition of fixed nitrogen and under the initial oxygen concentrations of $4 \%, 6 \%$ or air $(20.8 \%)$.

\section{RNA extraction and RT-PCR}

Strains were grown under $4 \%$ of oxygen for six hours. Cells from $30 \mathrm{~mL}$ of culture were collected by centrifugation (7000 rpm, $4^{\circ} \mathrm{C}, 5$ minutes) and re-suspended in $200 \mu \mathrm{L}$ of $10 \mathrm{mM}$ Trizma $^{\circ}$ (Sigma\# T-2694). The cells were then mixed with $700 \mu \mathrm{L}$ of RLT Buffer (Qiagen Rneasy Mini Kit \#74104) containing $1 \%$ of $\beta$-mercaptoethanol and added to lysing tubes containing zirconia and silica/glass beads in the proportion of 2:1 (Thistle Scientific Ltd). Lysis was carried out with 3 pulses (speed 6.5 with 30 seconds on/ 1.5 minutes off) using the Thermo Savant FastPrep 120 Cell Disrupter System. Beads and cellular debris were collected by centrifugation $\left(17000 \times g, 4^{\circ} \mathrm{C}, 5 \mathrm{~min}\right)$. The supernatant $(900 \mu \mathrm{L})$ was transferred to a new RNase free tube and $450 \mu \mathrm{L}$ of ethanol (Sigma \#459844) was then added. The samples were applied to the RNeasy columns (Qiagen RNeasy Mini Kit \#74104) and total RNA was recovered after on column DNAse treatment with the Qiagen RNaseFree DNase set (\#79254) following the manufacturer's instructions. The quality of purified RNA was accessed by electrophoresis in a $1 \%$ agarose gel. RNA was treated with Turbo DNase (Ambion\#AM1907) following manufacturer's instructions and further purified with Qiagen RNeasy columns to avoid carryover of divalent cations.

Approximately $0.25 \mathrm{ng} / \mu \mathrm{L}$ of total RNA was used for direct RT-PCR using the One-Step RT-PCR kit (Qiagen \#210210) according to the manufacturer's instructions. Expression of nifH gene was evaluated using 16S rRNA as endogenous control. The primers are listed in the Additional file 6 .

\section{Preparation of protein extracts and western blotting}

$H$. seropedicae cultures adjusted to an O.D $D_{600}$ of 0.2 were grown under $4 \%$ of oxygen for six hours. After incubation, approximately $3 \mathrm{~mL}$ of cells (volumes were adjusted as necessary) were collected by centrifugation $(17000 \times g$, $2 \mathrm{~min}$ ), re-suspended in $100 \mu \mathrm{L}$ of protein sample buffer (120 mM of Tris- $\mathrm{HCl} \mathrm{pH}$ 6.8, 2\% SDS, 20\% Glycerol, 9\% $\beta$-mercaptoethanol and $0.03 \%$ bromophenol blue) and boiled for 5 minutes. Subsequently, $10 \mu \mathrm{L}$ of the resulting extract was loaded onto 12\% SDS-PAGE for resolution of the proteins, which were immediately transferred to a
PVDF membrane and then hybridized with ANTI-FLAG ${ }^{\circ}$ (Sigma \#7425) primary antibody (1/2500 dilution), followed by secondary anti-rabbit-HRP conjugated antibody (1/ 10000 dilution). The HRP activity was detected using the ECL Plus Western Blotting detection kit (GE Healthcare \#RPN2132) as indicated by the manufacturer and the UVP ${ }^{\circ}$ gel imaging system.

\section{Oxygen consumption measurements}

For determination of the oxygen consumption we designed two assays. First we evaluated the depletion of the oxygen levels in the gas phase of culture flasks sealed with Subaseal septa. Every hour we took a $0.5 \mathrm{ml}$ gas sample from the growing culture and analyzed the oxygen concentration by gas chromatography (Varian GC-450) coupled to a molecular sieve column and a TCD detector. Oxygen depletion was linear until 10 hours growth. The rate of consumption was calculated as the amount of oxygen consumed in the gas phase normalized by the protein concentration of the culture. A measurement of the dissolved oxygen consumption was also carried out with a Clark-type electrode. After addition of $100 \mu \mathrm{l}$ of bacterial culture into the chamber, containing $1.6 \mathrm{ml}$ of NFbHP-Malate at $30^{\circ} \mathrm{C}$, the consumption of dissolved oxygen in the medium was recorded until the polarizing voltage reached 0 (i.e. $0 \%$ oxygen saturation).

\section{Additional files}

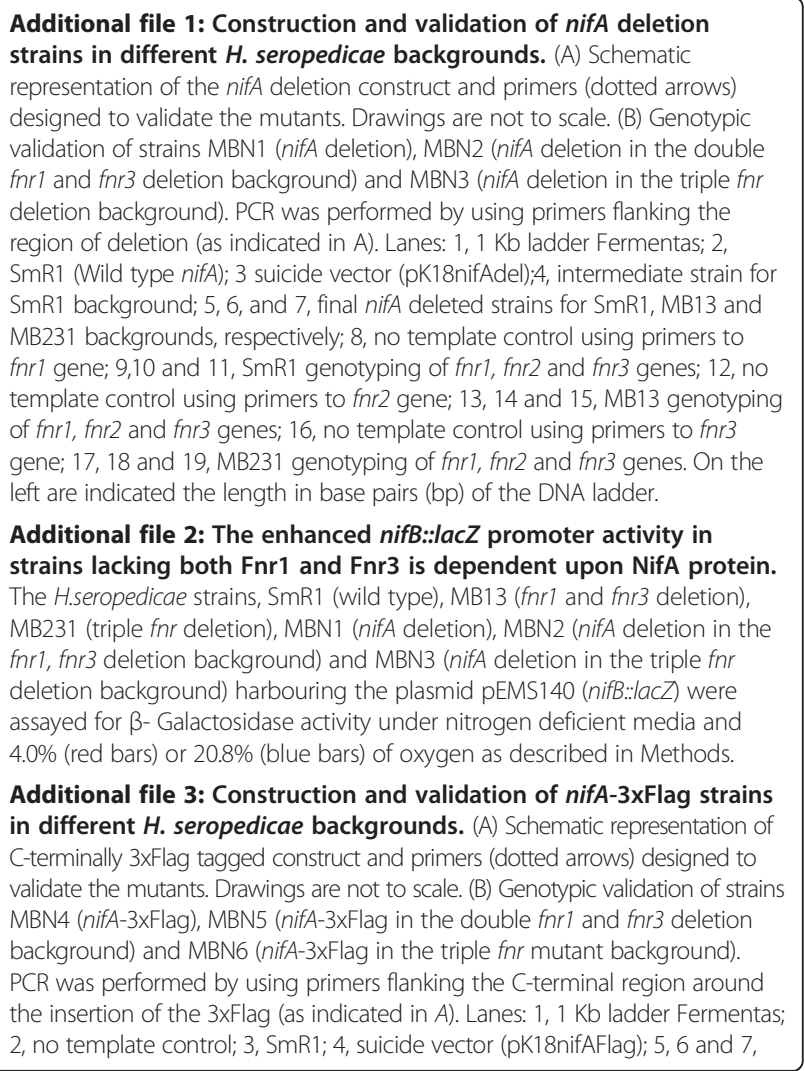


intermediate strains for SmR1, MB13 and MB231 backgrounds; 8,9 and 10, final 3xFlag tagged strains for SmR1, MB13 and MB231 backgrounds. The fnr genotypes on different nifA-3XFlag backgrounds were verified as showed on Additional file 1. On the left are indicated the length in base pairs (bp) of the DNA ladder.

Additional file 4: Deletion of $f n r$ genes influences the diazotrophic growth profile. Both H. seropedicae wild type strain (SmR1) (black squares) and the triple fnr mutant strain (MB231) (red triangles) were incubated statically at $30^{\circ} \mathrm{C}$ in NFbHP-Malate minimal media without addition of nitrogen source.

Additional file 5: Construction and validation of fnr1-3xFlag strain from $\mathrm{H}$. seropedicae. (A) Schematic representation of C-terminally 3xFlag tagged construct and primers (dotted arrows) designed to validate the mutant. Drawings are not to scale. (B) Genotypic validation of the strain MBF1 (fnr1-3xFlag). PCR was performed by using primers flanking the C-terminal region around the insertion of the $3 \times$ Flag (as indicated in A). Lanes: 1, 1 Kb ladder Fermentas; 2, SmR1; 3, suicide vector (pJQfnr1Flag); 4, intermediate strain and 5 final fnr1-3xFlag tagged strain (MBF1). On the left are indicated the length in base pairs (bp) of the DNA ladder.

\section{Additional file 6: Primers used in this study.}

\section{Competing interests}

The authors declare that they have no competing interests.

\section{Authors' contributions}

MBB designed the study, performed experiments, analysed the data and wrote the manuscript. RW and FOP participated in study design and data analysis. EMS, RD and RAM designed the study, analysed the data and wrote the manuscript. All authors read and approved the final manuscript.

\section{Acknowledgments}

This study was supported by the Brazilian Program of National Institutes of Science and Technology-INCT/Brazilian Research Council-CNPq/MCT, CNPq, Fundação Araucária, CAPES. MBB is also grateful to the PhD and academic mobility fellowships provided by CNPq and the Brazilian program Science without Borders, respectively. Roseli A. Prado, Marilza D. Lamour and Valter A. de Baura are acknowledged for the technical assistance.

\section{Author details}

'Department of Biochemistry and Molecular Biology, Universidade Federal do Paraná, P.O. Box 19046, Curitiba, PR 81531-990, Brazil. ²Department of Molecular Microbiology, John Innes Centre, Colney Lane, Norwich NR4 7UH, UK. ${ }^{3}$ Department of Genetics, Universidade Federal do Paraná, P.O. Box 19071, Curitiba, PR 81531-990, Brazil.

Received: 16 December 2014 Accepted: 24 April 2015

Published online: 07 May 2015

\section{References}

1. Chubatsu LS, Monteiro RA, Souza EM, Oliveira MAS, Yates MG, Wassem R, et al. Nitrogen fixation control in Herbaspirillum seropedicae. Plant Soil. 2012;356:197-207.

2. Monteiro RA, Balsanelli E, Wassem R, Marin AM, Brusamarello-Santos LCC, Schmidt MA, et al. Herbaspirillum-plant interactions: microscopical, histological and molecular aspects. Plant Soil. 2012;356:175-96.

3. Roncato-Maccari LDB, Ramos HJO, Pedrosa FO, Alquini Y, Chubatsu LS, Yates $M G$, et al. Endophytic Herbaspirillum seropedicae expresses nif genes in gramineous plants. FEMS Microbiol Ecol. 2003;45:39-47.

4. Pedrosa FO, Monteiro RA, Wassem R, Cruz LM, Ayub RA, Colauto NB, et al. Genome of Herbaspirillum seropedicae strain SmR1, a specialized diazotrophic endophyte of tropical grasses. PLoS Genet. 2011;7, e1002064.

5. Bush M, Dixon R. The role of bacterial enhancer binding proteins as specialized activators of o54-dependent transcription. Microbiol Mol Biol Rev. 2012;76:497-529.

6. Rego FGM, Pedrosa FO, Chubatsu LS, Yates MG, Wassem R, Steffens MBR, et al. The expression of nifB gene from Herbaspirillum seropedicae is dependent upon the NifA and RpoN proteins. Can J Microbiol. 2006;52:1199-207.
7. Machado IM, Yates MG, Machado HB, Souza EM, Pedrosa FO. Cloning and sequencing of the nitrogenase structural genes nifHDK of Herbaspirillum seropedicae. Braz J Med Biol Res. 1996;29:1599-602.

8. Souza EM, Pedrosa FO, Drummond M, Rigo LU, Yates MG. Control of Herbaspirillum seropedicae NifA activity by ammonium ions and oxygen. J Bacteriol. 1999;181:681-4.

9. Dixon R, Kahn D. Genetic regulation of biological nitrogen fixation. Nat Rev Microbiol. 2004;2:621-31.

10. Lazazzera BA, Beinert H, Khoroshilova N, Kennedy MC, Kiley PJ. DNA binding and dimerization of the Fe-S-containing FNR protein from Escherichia coli are regulated by oxygen. J Biol Chem. 1996;271:2762-8.

11. Korner H, Sofia HJ, Zumft WG. Phylogeny of the bacterial superfamily of CrpFnr transcription regulators: exploiting the metabolic spectrum by controlling alternative gene programs. FEMS Microbiol Rev. 2003;27:559-92.

12. Spiro $S$. The FNR family of transcriptional regulators. Antonie Van Leeuwenhoek. 1994;66:23-36.

13. Spiro S, Guest JR. FNR and its role in oxygen-regulated gene expression in Escherichia coli. FEMS Microbiol Lett. 1990;75:399-428.

14. Matsui M, Tomita M, Kanai A. Comprehensive computational analysis of bacterial CRP/FNR superfamily and its target motifs reveals stepwise evolution of transcriptional networks. Genome Biol Evol. 2013;5:267-82.

15. Grabbe R, Klopprogge KAl, Schmitz RA. Fnr is required for NifL-dependent oxygen control of nif gene expression in Klebsiella pneumoniae. J Bacteriol. 2001;183:1385-1393.

16. Mesa S, Hauser F, Friberg M, Malaguti E, Fischer H-M, Hennecke H. Comprehensive assessment of the regulons controlled by the FixL-FixK2-FixK1 cascade in Bradyrhizobium japonicum. J Bacteriol. 2008;190:6568-79.

17. Monteiro RA, Souza EM, Yates MG, Pedrosa FO, Chubatsu LS. Fnr is involved in oxygen control of Herbaspirillum seropedicae N-truncated NifA protein activity in Escherichia coli. Appl Environ Microbiol. 2003;69:1527-31.

18. Batista MB, Sfeir MZT, Faoro H, Wassem R, Steffens MBR, Pedrosa FO, et al. The Herbaspirillum seropedicae SmR1 Fnr orthologs controls the cytochrome composition of the electron transport chain. Sci Rep. 2013;3:2544.

19. Oliveira MAS, Baura VA, Aquino B, Huergo LF, Kadowaki MAS, Chubatsu LS, et al. Role of conserved cysteine residues in Herbaspirillum seropedicae NifA activity. Res Microbiol. 2009;160:389-95.

20. Wassem R, Pedrosa FO, Yates MG, Rego FGM, Chubatsu LS, Rigo LU, et al. Control of autogenous activation of Herbaspirillum seropedicae nifA promoter by the IHF protein. FEMS Microbiol Lett. 2002;212:177-82.

21. Klassen G, Pedrosa FO, Souza EM, Funayama S, Rigo LU. Effect of nitrogen compounds on nitrogenase activity in Herbaspirillum seropedicae SMR1. Can J Microbiol. 1997;43:887-91.

22. Schäfer A, Tauch A, Jäger W, Kalinowski J, Thierbach G, Pühler A. Small mobilizable multi-purpose cloning vectors derived from the Escherichia coli plasmids pK18 and pK19: selection of defined deletions in the chromosome of Corynebacterium glutamicum. Gene. 1994;145:69-73.

23. Quandt J, Hynes MF. Versatile suicide vectors which allow direct selection for gene replacement in Gram-negative bacteria. Gene. 1993;127:15-21.

24. Souza EM, Pedrosa FO, Rigo LU, Machado HB, Yates MG. Expression of the nifA gene of Herbaspirillum seropedicae: role of the $\mathrm{NtrC}$ and NifA binding sites and of the -24/-12 promoter element. Microbiology. 2000;146(Pt 6):1407-18.

25. Estabrook RW. Mitochondrial respiratory control and the polarographic measurement of ADP : O ratios. Methods Enzymol. 1967;10:41-7.

26. Noindorf L, Bonatto AC, Monteiro RA, Souza EM, Rigo LU, Pedrosa FO, et al. Role of Pll proteins in nitrogen fixation control of Herbaspirillum seropedicae strain SmR1. BMC Microbiol. 2011;11:8.

27. Woodley P, Buck M, Kennedy C. Identification of sequences important for recognition of vnf genes by the VnfA transcriptional activator in Azotobacter vinelandii. FEMS Microbiol Lett. 1996;135:213-21. 